\title{
Correction to: Fabrication of Gel-like Emulsions with Whey Protein Isolate Using Microfluidization: Rheological Properties and 3D Printing Performance
}

\author{
Yaowei Liu ${ }^{1,2} \cdot$ Wenjin Zhang ${ }^{1,2} \cdot$ Keyu Wang ${ }^{1,2} \cdot$ Yulong Bao $^{1,2} \cdot$ Joe Mac Regenstein ${ }^{2,3} \cdot$ Peng Zhou ${ }^{1,2}$ (D)
}

Published online: 5 November 2019

(C) Springer Science+Business Media, LLC, part of Springer Nature 2019

\section{Correction to: Food and Bioprocess Technology}

https://doi.org/10.1007/s11947-019-02344-5

The original version of this article unfortunately contained some mistakes. The Fig. 7 was published with incomplete content due to incorrect image processing.

With this, the correct Fig. 7 is hereby published.

The online version of the original article can be found at https://doi.org/ $10.1007 / \mathrm{s} 11947-019-02344-5$

Peng Zhou

zhoupeng@jiangnan.edu.cn

1 State Key Laboratory of Food Science \& Technology, Jiangnan University, Wuxi 214122, Jiangsu Province, China

2 International Joint Research Laboratory for Functional Dairy Protein Ingredients, Jiangnan University, Wuxi 214122, Jiangsu Province, China

3 Department of Food Science, Cornell University, Ithaca, NY 14853-7201, USA 

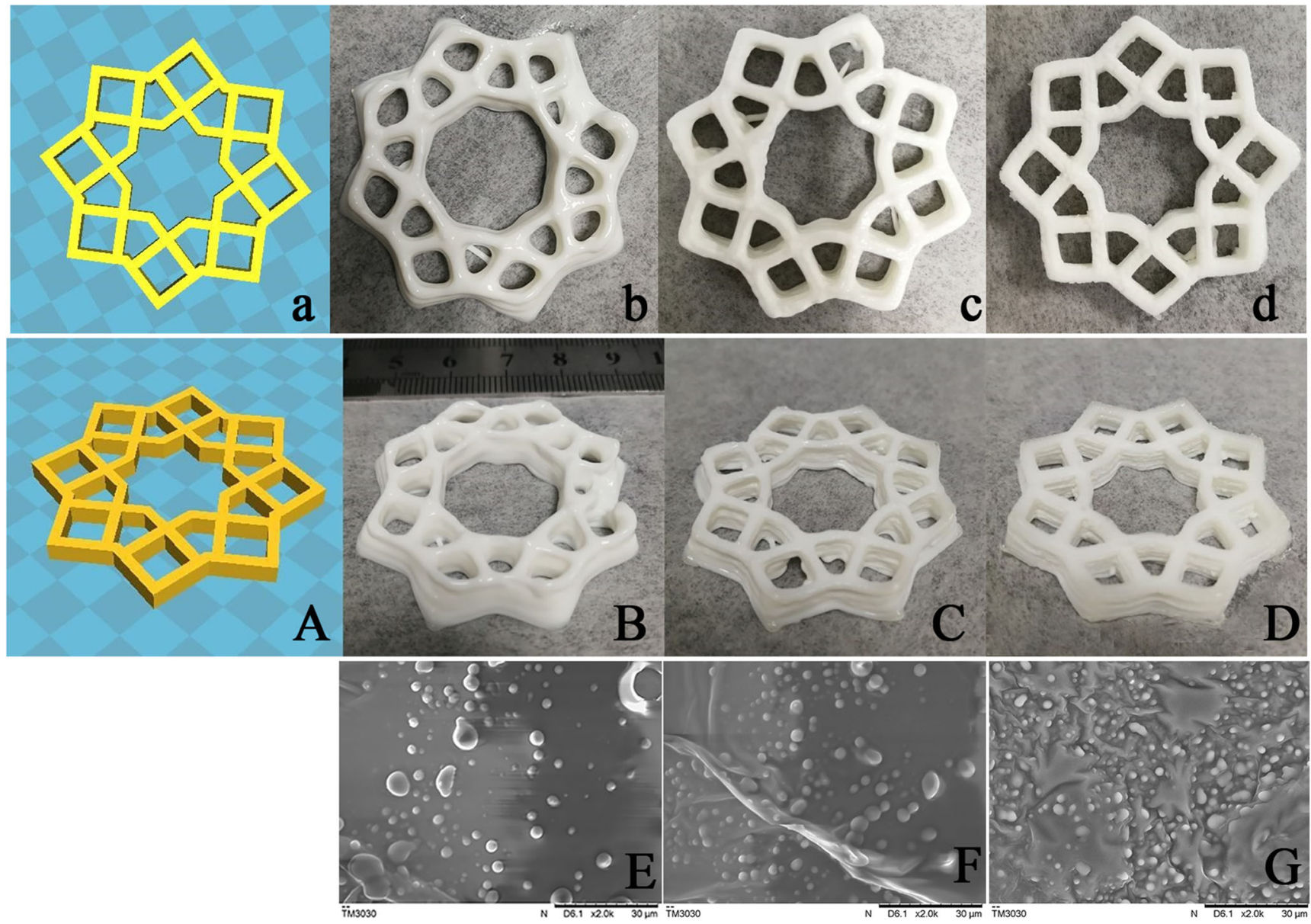

Publisher's Note Springer Nature remains neutral with regard to jurisdictional claims in published maps and institutional affiliations. 